\title{
del Nido versus Buckberg cardioplegia in adult isolated valve surgery
}

\author{
Stephanie L. Mick, MD, ${ }^{a}$ Michael P. Robich, MD, MSPH, ${ }^{a}$ Penny L. Houghtaling, MS, ${ }^{b}$ \\ A. Marc Gillinov, MD, ${ }^{a}$ Edward G. Soltesz, MD, MPH, ${ }^{\mathrm{a}}$ Douglas R. Johnston, MD, ${ }^{\mathrm{a}}$ \\ Eugene H. Blackstone, MD, a,b and Joseph F. Sabik III, MD ${ }^{\mathrm{a}}$
}

Background: del Nido solution is a non-glucose-based, single-dose cardioplegic solution with few data supporting its safety in adults. We hypothesized that it and Buckberg solution offer myocardial protection of equivalent safety for isolated adult valve surgery.

\begin{abstract}
Methods: Adult patients undergoing primary isolated aortic or mitral valve surgery with del Nido or Buckberg solution from January 2010 to September 2013 were 1:1 propensity matched ( 85 aortic valve, 110 mitral valve), and outcomes were compared.

Results: After aortic valve operations, no hospital deaths occurred, and troponin T levels (median $0.19 \mathrm{ng}$. $\mathrm{mL}^{-1}$ for del Nido vs $0.21 \mathrm{ng} \cdot \mathrm{mL}^{-1}$ for Buckberg) were similar, with no statistically significant change in left ventricular ejection fraction $(P=.4)$. Aortic clamp, bypass, and operating room times were shorter with del Nido solution ( $44 \pm 14$ vs $56 \pm 19 ; 56 \pm 18$ vs $70 \pm 24$; and $285 \pm 44$ vs $308 \pm 61$ minutes, respectively; $P<.0001)$. Peak intraoperative glucose levels $\left(170 \pm 31 \mathrm{vs} 240 \pm 41 \mathrm{mg} \cdot \mathrm{dL}^{-1} ; P<.0001\right)$ and postoperative insulin-drip requirements $(46 \%$ vs $82 \% ; P<.0001)$ were lower. After mitral operations, there were no hospital deaths and no statistically significant cardioplegia-specific changes in troponin T levels (median $0.37 \mathrm{ng} \cdot \mathrm{mL}^{-1}$ for del Nido vs $0.4 \mathrm{ng} \cdot \mathrm{mL}^{-1}$ for Buckberg) or postoperative left ventricular ejection fraction $(P=.13)$. We found no clear time differences with del Nido solution in mitral cases, but intraoperative glucose levels and postoperative insulin-drip requirements ( $184 \pm 37 \mathrm{vs} 250 \pm 60 \mathrm{mg} \cdot \mathrm{dL}^{-1}$ and $50 \% \mathrm{vs} 67 \% \mathrm{mg} \cdot \mathrm{dL}^{-1}$, respectively; $P=.009)$ were lower.
\end{abstract}

Conclusions: del Nido solution can be used safely and effectively as an alternative to Buckberg solution in adult isolated valve surgery and is associated with lower insulin requirements and potential time and cost savings. (J Thorac Cardiovasc Surg 2015;149:626-36)

See related commentary on pages $637-8$.

From the Department of Thoracic and Cardiovascular Surgery, ${ }^{\mathrm{a}}$ Heart and Vascular Institute, and Department of Quantitative Health Sciences, ${ }^{\mathrm{b}}$ Research Institute, Cleveland Clinic, Cleveland, Ohio.

This study was funded in part by the Sheikh Hamdan bin Rashid Al Maktoum Distinguished Chair in Thoracic and Cardiovascular Surgery, held by Dr Sabik, and the Kenneth Gee and Paula Shaw, PhD, Chair in Heart Research, held by Dr Blackstone. These individuals had no authority to approve or disapprove publication of the finished article.

Disclosures: Douglas R. Johnston reports consulting fees from St. Jude, Edwards, and Jack Medical, and equity ownership in Jack Medical. Joseph F. Sabik III reports consulting fees from Medtronic and Sorin, lecture fees from Medtronic and Medistim, and equity owbnership in Valve Exchange. A. Marc Gillinov reports consulting fees from On-X, Abbott, Atricure, and Tendyne, and lecture fees from Edwards, Medtronic, and St. Jude. Edward G. Soltesz reports consulting and lecture fees from St. Jude, Edwards, and Atricure. All other authors have nothing to disclose with regard to commercial support.

Read at the 40th Annual Meeting of The Western Thoracic Surgical Association, Dana Point, California, June 25-28, 2014.

Received for publication June 24, 2014; revisions received Oct 7, 2014; accepted for publication Oct 18, 2014; available ahead of print Dec 4, 2014.

Address for reprints: Stephanie L. Mick, MD, Department of Thoracic and Cardiovascular Surgery, Cleveland Clinic, 9500 Euclid Ave, Desk J4-1, Cleveland, OH 44195 (E-mail: micks@ccf.org).

0022-5223/\$36.00

Copyright (C) 2015 by The American Association for Thoracic Surgery

http://dx.doi.org/10.1016/j.jtcvs.2014.10.085
Supplemental material is available online.

At our institution, Buckberg cardioplegic solution ${ }^{1-3}$ has been the standard used in adult cardiac surgery for several decades. An induction dose is given (mixed with patient blood in a 1:4 ratio; Table 1) to arrest the heart; a maintenance solution is administered every 15 to 20 minutes thereafter. During a typical procedure, multiple doses are given, which may interrupt the flow of the operation. A reperfusion solution is administered just before release of the aortic clamp.

An alternative, del Nido solution, ${ }^{4}$ has also been used for decades in other institutions, primarily for pediatric heart surgery. It is administered as a single dose that is said to last up to 180 minutes. It is a calcium-free, potassiumrich, non-glucose-based solution (in contrast to Buckberg solution, which is dextrose-based) and has an electrolyte composition similar to extracellular fluid (Table 1). It is delivered along with fully oxygenated patient blood in a 4:1 ratio, providing potassium-based myocyte depolarization with concurrent lidocaine sodium channel blockade. Just as Buckberg solution has additives for substrate 


\section{Abbreviations and Acronyms \\ $\mathrm{CPB}=$ cardiopulmonary bypass \\ LA $=$ left atrial \\ $\mathrm{LV}=$ left ventricular \\ $\mathrm{LVEF}=$ left ventricular ejection fraction \\ $\mathrm{SD}=$ standard deviation}

enhancement, calcium regulation, and buffering, del Nido solution contains additives to effect free-radical scavenging, calcium channel blockade, and buffering (Table 1). ${ }^{4}$

Given the ease of administration, and the potential for reducing surgical interruption and cost, interest in del Nido solution has been increasing in the adult cardiac community. ${ }^{4}$ Although there is a large body of unpublished experience regarding its use in adults at some centers, and a small amount of animal data, ${ }^{5,6}$ published clinical data are scant. No randomized trial has been launched to investigate the comparative safety of these 2 cardioplegia methods. Therefore, to estimate sample size and other details to facilitate such a trial, the present propensitymatched study addresses whether del Nido solution provides myocardial protection equivalent to that of Buckberg solution during primary isolated cardiac valve surgery.

\section{PATIENTS AND METHODS \\ Patients}

From August 29, 2012, to September 1, 2013, a total of 394 patients underwent surgery in which del Nido solution was used, including isolated valve procedures, septal myectomies, maze procedures, limited aortic procedures, and multiple valve procedures. Of these, 205 received del
Nido solution, 89 for aortic valve procedures and 116 for mitral valve procedures. These isolated aortic and mitral valve operations are the focus of our study.

To find a sufficient number of patients for propensity matching, we expanded the inclusion criteria for Buckberg cardioplegia to 2010. From January 1, 2010, to September 1, 2013, a total of 2429 patients underwent primary isolated valve surgery. Of these, 2224 received Buckberg solution, 1074 for aortic valve procedures (Table E1) and 1150 for mitral valve procedures (Table E2).

\section{Data}

Data were retrieved from the prospective Cleveland Clinic Cardiovascular Information Registry and the Anesthesia Record Keeping System, and were intraoperatively collected from quality improvement records. All data were approved for use in research by the institutional review board, with patient consent waived. Patient characteristic variables and in-hospital outcomes were as defined by The Society of Thoracic Surgeons National Adult Cardiac Surgery Database.

\section{Surgical Technique}

Conventional general anesthesia was used in all patients regardless of surgical approach. The surgical approach (full sternotomy or upper hemisternotomy for aortic valve operations and full sternotomy, partial sternotomy, right thoracotomy, or robotic for mitral valve operations) was chosen by the surgeon. Although the details of cardioplegia administration varied, in general, antegrade and retrograde induction doses of Buckberg solution were administered (approximately 500 to $600 \mathrm{~mL}$ each), with maintenance doses (approximately $400 \mathrm{~mL}$ ) given every 15 to 20 minutes thereafter. Controlled warm reperfusion in the form of reanimation or "hotshot" cardioplegia (approximately 300-400 mL, with both retrograde and antegrade delivery) was generally performed before removal of the aortic clamp. In general, del Nido solution was administered in a single antegrade dose (generally $1000 \mathrm{~mL}$ ). Redosing (Appendix E1) of del Nido solution and systemic cooling were performed at the discretion of the surgeon; however, by and large, systemic hypothermia was not used in either group.

Intraoperative transfusion, fluid administration, and use of inotropes and pressors were carried out at the discretion of the anesthesiologists.

TABLE 1. Cardioplegia compositions

\begin{tabular}{|c|c|c|c|}
\hline \multicolumn{2}{|c|}{ Buckberg solution } & \multicolumn{2}{|c|}{ del Nido solution } \\
\hline Cold induction & & Components & \\
\hline D5 $1 / 4 \mathrm{NS}$ & $392 \mathrm{~mL}$ & Plasma-Lyte A & $1200 \mathrm{~mL}$ \\
\hline Tromethamine $0.3 \mathrm{M}$ & $60 \mathrm{~mL}$ & Mannitol $20 \%\left(3.2 \mathrm{~g} \cdot \mathrm{L}^{-1}\right)$ & $16 \mathrm{~mL}$ \\
\hline C-P-2-D & $30 \mathrm{~mL}$ & $\mathrm{MgSO}_{4} 50 \%\left(2 \mathrm{~g} \cdot \mathrm{L}^{-1}\right)$ & $4 \mathrm{~mL} \cdot \mathrm{L}^{-1}$ \\
\hline $\mathrm{KCl}\left(2 \mathrm{mEq} \cdot \mathrm{mL}^{-1}\right)$ & $36 \mathrm{mEq}$ & $\mathrm{NaHCO}_{3}\left(1 \mathrm{mEq} \cdot \mathrm{mL}^{-1}\right)$ & $13 \mathrm{~mL} \cdot \mathrm{L}^{-1}$ \\
\hline Total volume & $500 \mathrm{~mL}$ & $\mathrm{KCl}\left(2 \mathrm{mEq} \cdot \mathrm{mL}^{-1}\right)$ & $13 \mathrm{~mL} \cdot \mathrm{L}^{-1}$ \\
\hline Maintenance & & Lidocaine $2 \%$ & $7.8 \mathrm{~mL}$ \\
\hline D5 $1 / 4 \mathrm{NS}$ & $798 \mathrm{~mL}$ & Volume given & $20 \mathrm{~mL} \cdot \mathrm{kg}^{-1}$ up to maximum dose of $1000 \mathrm{~mL}$ \\
\hline Tromethamine $0.3 \mathrm{M}$ & $123 \mathrm{~mL}$ & & \\
\hline C-P-2-D & $61 \mathrm{~mL}$ & & \\
\hline $\mathrm{KCl}\left(2 \mathrm{mEq} \cdot \mathrm{mL}^{-1}\right)$ & $36 \mathrm{mEq}$ & & \\
\hline Total volume & $1000 \mathrm{~mL}$ & & \\
\hline \multicolumn{4}{|l|}{ Reperfusion } \\
\hline $70 \%$ dextrose & $26 \mathrm{~mL}$ & & \\
\hline Tromethamine $0.3 \mathrm{M}$ & $56 \mathrm{~mL}$ & & \\
\hline C-P-2-D & $113 \mathrm{~mL}$ & & \\
\hline $\mathrm{KCl}\left(2 \mathrm{mEq} \cdot \mathrm{mL}^{-1}\right)$ & $15 \mathrm{mEq}$ & & \\
\hline Glutamate/aspartate & $62.5 \mathrm{~mL}$ & & \\
\hline Total volume & $500 \mathrm{~mL}$ & & \\
\hline
\end{tabular}

$D 5,5 \%$ Dextrose solution; $N S$, normal saline; $C-P-2-D$, citrate-phosphate-2-dextrose. 
TABLE 2. Characteristics and operative details of matched patients undergoing aortic valve surgery

\begin{tabular}{|c|c|c|c|c|c|}
\hline \multirow[b]{2}{*}{ Variable } & \multicolumn{2}{|c|}{ Buckberg group $(\mathbf{n}=\mathbf{8 5})$} & \multicolumn{2}{|c|}{ del Nido group $(\mathbf{n}=\mathbf{8 5})$} & \multirow[b]{2}{*}{$P$ valu } \\
\hline & $\mathbf{n}^{*}$ & No. $(\%)$ or mean \pm SD & $\mathbf{n}^{*}$ & No. $(\%)$ or mean \pm SD & \\
\hline \multicolumn{6}{|l|}{ Demographics } \\
\hline Women & 85 & $24(28)$ & 85 & $26(31)$ & .7 \\
\hline Age (y) & 85 & $68 \pm 15$ & 85 & $69 \pm 14$ & .8 \\
\hline Body mass index $\left(\mathrm{kg} \cdot \mathrm{m}^{-2}\right)$ & 85 & $29 \pm 8.1$ & 85 & $29 \pm 6.6$ & .8 \\
\hline NYHA functional class & 72 & & 85 & & .2 \\
\hline I & & $24(33)$ & & $22(26)$ & \\
\hline II & & $24(33)$ & & $42(49)$ & \\
\hline III & & $21(29)$ & & $19(22)$ & \\
\hline IV & & $3(4.2)$ & & $2(2.4)$ & \\
\hline \multicolumn{6}{|l|}{ Aortic valve pathophysiology } \\
\hline Aortic valve area $\left(\mathrm{cm}^{2}\right)$ & 74 & $0.76 \pm 0.41$ & 79 & $0.78 \pm 0.40$ & .8 \\
\hline Mean aortic valve gradient $(\mathrm{mm} \mathrm{Hg})$ & 79 & $48(36,63) \dagger$ & 82 & $51(36,63) \dagger$ & .2 \\
\hline Peak aortic valve gradient $(\mathrm{mm} \mathrm{Hg})$ & 80 & $80 \pm 26$ & 82 & $84 \pm 27$ & .17 \\
\hline \multicolumn{6}{|l|}{ Cardiovascular comorbidity } \\
\hline Calculated LV relative wall thickness $(\mathrm{cm})$ & 80 & $0.52 \pm 0.16$ & 83 & $0.54 \pm 0.14$ & .3 \\
\hline LV ejection fraction $(\%)$ & 83 & $57 \pm 8.5$ & 84 & $58 \pm 9.8$ & .4 \\
\hline Calculated LV mass (g) & 80 & $223 \pm 86$ & 83 & $224 \pm 71$ & 6 \\
\hline Atrial fibrillation or flutter & 84 & $7(8.3)$ & 85 & $10(12)$ & .5 \\
\hline Peripheral arterial disease & 85 & $14(16)$ & 85 & $13(15)$ & .8 \\
\hline Hypertension & 85 & $76(89)$ & 85 & $80(94)$ & .3 \\
\hline \multicolumn{6}{|l|}{ Noncardiac comorbidity } \\
\hline Diabetes & 85 & & 85 & & \\
\hline Pharmacologically treated & & $18(21)$ & & $17(20)$ & .8 \\
\hline Insulin treated & & $5(5.9)$ & & $6(7.1)$ & .8 \\
\hline Non-insulin treated & & $16(19)$ & & $13(15)$ & .5 \\
\hline Potassium $\left(\mathrm{mmol} \cdot \mathrm{L}^{-1}\right)$ & 84 & $4.2 \pm 0.60$ & 85 & $4.1 \pm 0.57$ & .4 \\
\hline Glucose $\left(\mathrm{mg} \cdot \mathrm{dL}^{-1}\right)$ & 85 & $106 \pm 27$ & 85 & $103 \pm 26$ & .5 \\
\hline Creatinine $\left(\mathrm{mg} \cdot \mathrm{dL}^{-1}\right)$ & 85 & $1.01 \pm 0.54$ & 85 & $0.98 \pm 0.26$ & $>.9$ \\
\hline Cockcroft-Gault creatinine clearance & 85 & $88 \pm 35$ & 85 & $87 \pm 34$ & .9 \\
\hline Hematocrit $(\%)$ & 85 & $40 \pm 4.5$ & 85 & $39 \pm 4.9$ & .9 \\
\hline \multicolumn{6}{|l|}{ Operative details } \\
\hline \multicolumn{6}{|l|}{ Aortic valve surgery } \\
\hline Repair & 85 & $6(7.1)$ & 85 & $6(7.1)$ & $>.9$ \\
\hline Replacement & 85 & $79(93)$ & 85 & $19(93)$ & $>.9$ \\
\hline \multicolumn{6}{|l|}{ Incision/approach } \\
\hline Full sternotomy & 85 & $8(9.4)$ & 85 & $9(11)$ & .8 \\
\hline Hemisternotomy & 85 & $77(91)$ & 85 & $76(89)$ & .8 \\
\hline Year of operation & 85 & & 85 & & $<.0001$ \\
\hline 2010 & & $12(14)$ & & $0(0)$ & \\
\hline 2011 & & $23(27)$ & & $0(0)$ & \\
\hline 2012 & & $38(45)$ & & $8(9.4)$ & \\
\hline 2013 & & $12(14)$ & & $77(91)$ & \\
\hline
\end{tabular}

Intraoperative insulin-drip administration was driven by protocol, which aimed at maintaining blood glucose between 70 and $150 \mathrm{mg} \cdot \mathrm{dL}^{-1}$, with insulin drip started for levels $>120 \mathrm{mg} \cdot \mathrm{dL}^{-1}$ before cardiopulmonary bypass (CPB), or for any single level $>150 \mathrm{mg} \cdot \mathrm{dL}^{-1}$ on or after CPB.

\section{Endpoints}

The primary endpoint assessed was highest postoperative in-hospital troponin T level. A sample was routinely obtained 6 to 12 hours postoperatively. Multiple samples were obtained only if clinically indicated. Secondary endpoints included in-hospital death and additional measures of myocardial injury (postoperative left ventricular ejection fraction
[LVEF] assessed by transthoracic echocardiography, use of post-CPB chemical inotropic/pressor therapy, and new-onset atrial fibrillation or flutter). Tertiary endpoints included intraoperative hematocrit levels, volumes of resuscitative fluid and red blood cell transfusions, trends in intraoperative glucose levels and immediate post-CPB insulin-drip requirements, and aortic clamp time, CPB time, and total operating room time.

\section{Data Analysis}

All analyses were performed using SAS statistical software (SAS version 9.2; SAS Institute, Cary, NC). 
TABLE 3. Characteristics and operative details of matched patients undergoing mitral valve surgery

\begin{tabular}{|c|c|c|c|c|c|}
\hline \multirow[b]{2}{*}{ Variable } & \multicolumn{2}{|c|}{ Buckberg group $(n=110)$} & \multicolumn{2}{|c|}{ del Nido group $(n=110)$} & \multirow[b]{2}{*}{$P$ value } \\
\hline & $\mathbf{n}^{*}$ & No. $(\%)$ or mean \pm SD & $\mathbf{n}^{*}$ & No. $(\%)$ or mean \pm SD & \\
\hline \multicolumn{6}{|l|}{ Demographics } \\
\hline Women & 110 & $40(36)$ & 110 & $32(29)$ & .3 \\
\hline Age (y) & 110 & $56 \pm 12$ & 110 & $56 \pm 12$ & .8 \\
\hline Body mass index $\left(\mathrm{kg} \cdot \mathrm{m}^{-2}\right)$ & 110 & $25 \pm 3.9$ & 110 & $26 \pm 3.5$ & .11 \\
\hline NYHA functional class & 101 & & 110 & & .2 \\
\hline I & & $59(58)$ & & $50(45)$ & \\
\hline II & & $37(37)$ & & $56(51)$ & \\
\hline III & & $4(44)$ & & $3(2.7)$ & \\
\hline IV & & $1(0.99)$ & & $1(0.91)$ & \\
\hline \multicolumn{6}{|l|}{ Mitral valve pathophysiology } \\
\hline \multicolumn{6}{|l|}{ Mitral regurgitation grade } \\
\hline $1+$ & 110 & $2(1.8)$ & 110 & $1(0.91)$ & .9 \\
\hline $2+$ & 110 & $2(1.8)$ & 110 & $2(1.8)$ & .9 \\
\hline $3+$ & 110 & $19(17)$ & 110 & $23(21)$ & .9 \\
\hline $4+$ & 110 & $87(79)$ & 110 & $84(76)$ & .8 \\
\hline Mitral stenosis & 110 & $1(0.91)$ & 110 & $1(1.8)$ & 6 \\
\hline \multicolumn{6}{|l|}{ Cardiovascular comorbidity } \\
\hline LV ejection fraction $(\%)$ & 109 & $59 \pm 5.9$ & 108 & $60 \pm 5.4$ & .3 \\
\hline Calculated LV mass (g) & 96 & $244 \pm 75$ & 102 & $227 \pm 70$ & .14 \\
\hline Atrial fibrillation or flutter & 110 & $5(4.5)$ & 110 & $0(0)$ & .04 \\
\hline Peripheral arterial disease & 110 & $5(4.5)$ & 110 & $4(3.6)$ & .7 \\
\hline Hypertension & 110 & $60(55)$ & 110 & $59(54)$ & .9 \\
\hline \multicolumn{6}{|l|}{ Noncardiac comorbidity } \\
\hline Diabetes & & & 110 & & \\
\hline Pharmacologically treated & 110 & $2(1.8)$ & 110 & $2(1.8)$ & $>.9$ \\
\hline Insulin treated & 110 & $0(0)$ & 109 & $1(0.92)$ & .3 \\
\hline Non-insulin treated & 110 & $2(1.8)$ & 109 & $1(0.92)$ & 6 \\
\hline Potassium $\left(\mathrm{mmol} \cdot \mathrm{L}^{-1}\right)$ & 109 & $4.1 \pm 0.52$ & 110 & $4.2 \pm 0.53$ & .7 \\
\hline Glucose $\left(\mathrm{mg} \cdot \mathrm{dL}^{-1}\right)$ & 110 & $92 \pm 14$ & 110 & $92 \pm 18$ & .5 \\
\hline Creatinine $\left(\mathrm{mg} \cdot \mathrm{dL}^{-1}\right)$ & 110 & $1.03 \pm 1.03$ & 110 & $1.02 \pm 0.79$ & .9 \\
\hline Cockcroft-Gault creatinine clearance & 110 & $92 \pm 25$ & 110 & $97 \pm 26$ & .19 \\
\hline Hematocrit $(\%)$ & 110 & $40 \pm 5.0$ & 110 & $41 \pm 4.9$ & .19 \\
\hline \multicolumn{6}{|l|}{ Operative details } \\
\hline \multicolumn{6}{|l|}{ Mitral valve surgery } \\
\hline Repair & 110 & $108(98)$ & 110 & $106(96)$ & .4 \\
\hline Replacement & 110 & $2(1.8)$ & 110 & $4(3.6)$ & .4 \\
\hline \multicolumn{6}{|l|}{ Incision/approach } \\
\hline Full sternotomy & 110 & $9(8.2)$ & 110 & $11(10)$ & 6 \\
\hline $\begin{array}{l}\text { Minimally invasive (hemisternotomy, } \\
\text { thoracotomy, or robotic) }\end{array}$ & 110 & $101(92)$ & 110 & $99(90)$ & 6 \\
\hline Robotic & 110 & $38(35)$ & 110 & $44(40)$ & .4 \\
\hline Year of operation & 110 & & 110 & & $<.0001$ \\
\hline 2010 & & $30(27)$ & & $0(0)$ & \\
\hline 2011 & & $23(21)$ & & $0(0)$ & \\
\hline 2012 & & $36(33)$ & & $16(15)$ & \\
\hline 2013 & & $21(19)$ & & $94(85)$ & \\
\hline
\end{tabular}

$S D$, Standard deviation; NYHA, New York Heart Association; $L V$, left ventricular. *Patients with data available.

Propensity-score development and use. To simulate a randomized trial, propensity-score methodology was used to construct comparable del Nido and Buckberg cardioplegia groups, separately for aortic valve replacement and mitral valve surgery. ${ }^{8}$ Multivariable logistic regression analysis was performed to identify patient characteristics associated with the del Nido group. Variables considered in the analyses are listed in Appendix E2. Initially, a parsimonious model was developed using automated analysis of 500 resampled data sets, followed by tabulating the frequency of occurrence at $P \leq .05$, of both single factors and closely related clusters of factors. ${ }^{9,10}$ Factors with $\geq 50 \%$ occurrence were retained in the parsimonious models. The only reliable factor associated with use of del Nido solution in aortic valve patients was a less invasive approach $(P<.0001)$; several variables, including approach, were associated with its use in the mitral valve 
group (Table E3).Thereafter, we augmented the parsimonious model with other variables representing patient demographics, symptoms, and cardiac and noncardiac comorbidities to form saturated models (Appendix E2).

A propensity score was then calculated for each patient by solving the saturated model for the probability of being in the del Nido group. Next, using only the propensity score, del Nido patients were matched to Buckberg patients using a greedy matching strategy ${ }^{11}$ without replacement. Patients whose propensity scores deviated by more than 0.15 were considered unmatched. This process yielded 85 well-matched pairs from the $89 \mathrm{del}$ Nido cases (96\% matched) for aortic valve replacement (Table 2), and 110 well-matched pairs from the 116 del Nido cases (95\% matched) for mitral valve surgery (Table 3 ). Propensity-matched patients in both valve groups were drawn from across the entire spectrum of propensity scores (Tables 2 and 3; Figure E1, $A$ and $B$ ), and patient pairs were wellmatched (Figure E2, $A$ and $B$ ).

Factors associated with myocardial injury. Cumulative distributions for all troponin values were constructed for unmatched and matched patient pairs. Linear regression models for postoperative troponin T were created that included cardioplegia group, myocardial ischemic time, and the interaction of cardioplegia group and myocardial ischemic time for each valve cohort of matched patients. Troponin values were $\log$-transformed for analysis because of their skewed distribution. Data transformations of the ischemic times were investigated (logarithmic, inverse, exponentials) to find the best model to fit the data.

Nested linear regression models were used to test group differences in postoperative LVEF (SAS PROC GLM). Within each valve cohort of matched patients, 2 models were constructed. The first model included preoperative LVEF, cardioplegia group, their interaction, and myocardial ischemic time. The second included only preoperative LVEF and myocardial ischemic time. The $\mathrm{F}$ test was used to test the hypothesis that the smaller model fit the data adequately and that the larger model (inclusion of cardioplegia group) is unnecessary.

\section{Presentation}

Continuous variables are summarized as mean \pm standard deviation (SD) or as equivalent 15th, 50th (median), and 85th percentiles when data were skewed; comparisons were made using the Wilcoxon rank sum test. Categoric data are summarized using frequencies and percentages; comparisons were made using the $\chi^{2}$ test or Fisher exact test when the frequency was $<5$.

\section{RESULTS}

\section{Myocardial Injury}

No patient died in either group. The highest measured postoperative troponin $\mathrm{T}$ level was higher after mitral valve surgery than after aortic valve surgery (Figure 1), but in matched patients within each valve group, the distribution of values was similar for del Nido and Buckberg patients (aortic valve, $0.19 \mathrm{vs} 0.21 \mathrm{ng} \cdot \mathrm{mL}^{-1}, P=.05$; mitral valve, $0.37 \mathrm{vs} 0.40 \mathrm{ng} \cdot \mathrm{mL}^{-1}, P=.2$ ), although slightly lower with del Nido cardioplegia in both valve surgery groups
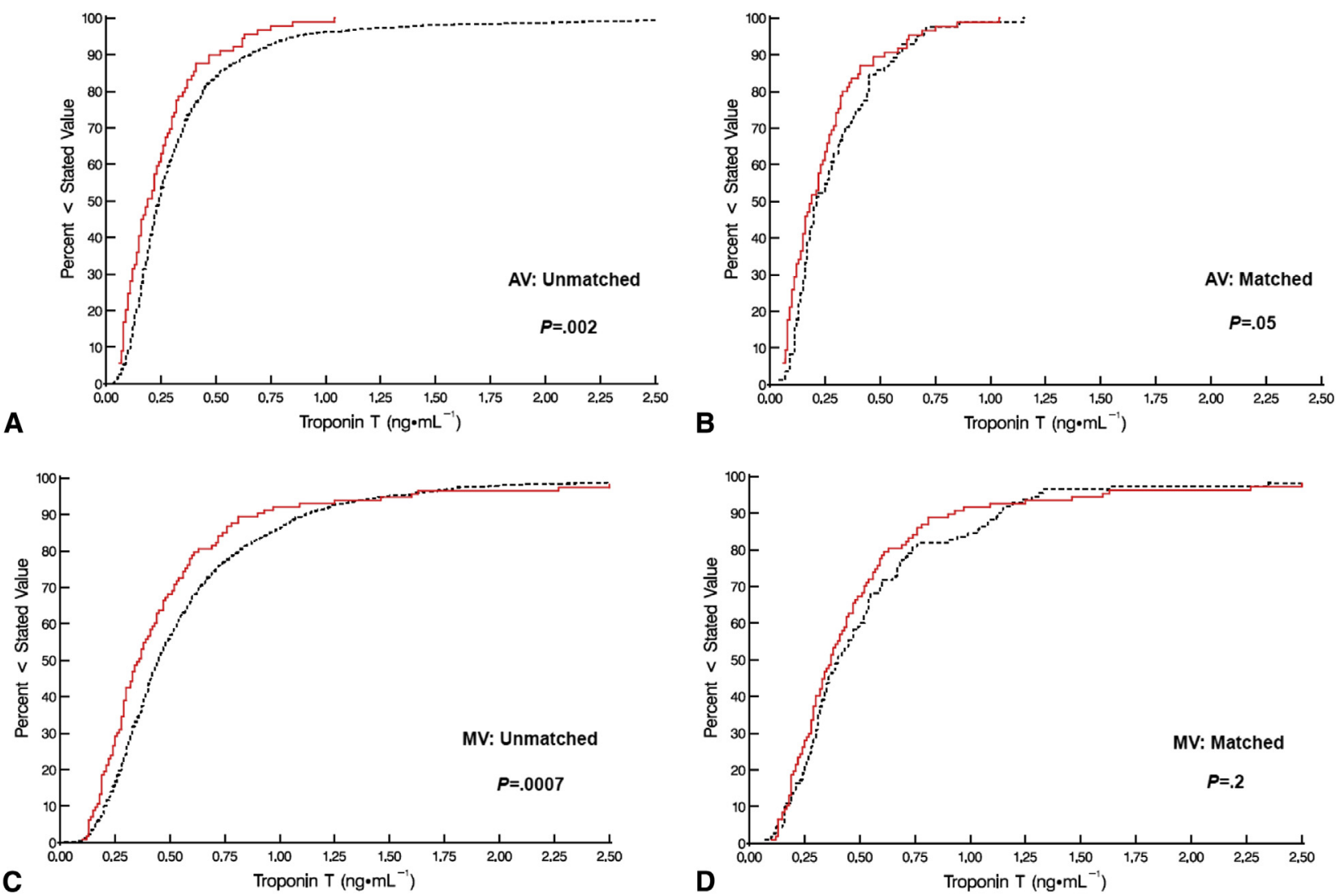

FIGURE 1. Highest measured troponin T levels after isolated AV and MV surgery: (A) after AV surgery, unmatched patients; (B) after AV surgery, propensity-matched patients; (C) after MV surgery, unmatched patients; (D) after MV surgery, propensity-matched patients. Solid lines represent patients receiving del Nido solution; dashed lines represent those receiving Buckberg solution. AV, Aortic valve; $M V$, mitral valve. 
TABLE 4. Management variables of matched patients undergoing aortic valve surgery

\begin{tabular}{|c|c|c|c|c|c|}
\hline \multirow[b]{2}{*}{ Variable } & \multicolumn{2}{|c|}{ Buckberg group $(n=85)$} & \multicolumn{2}{|c|}{ del Nido group $(n=85)$} & \multirow[b]{2}{*}{$P$ value } \\
\hline & $\mathbf{n}^{*}$ & No. $(\%)$ or mean \pm SD & $\mathbf{n}^{*}$ & No. $(\%)$ or mean \pm SD & \\
\hline \multicolumn{6}{|l|}{ Myocardial injury } \\
\hline Highest measured troponin $\mathrm{T}\left(\mathrm{ng} \cdot \mathrm{mL}^{-1}\right)$ & 84 & $0.11 / 0.21 / 0.48 \dagger$ & 85 & $0.08 / 0.19 / 0.41 \dagger$ & .05 \\
\hline \multicolumn{6}{|l|}{ Inotropic and vasoactive agents } \\
\hline Epinephrine & 85 & $15(18)$ & 85 & $12(14)$ & .5 \\
\hline Norepinephrine & 85 & $21(25)$ & 85 & $26(31)$ & .4 \\
\hline Milrinone & 85 & $5(5.9)$ & 85 & $2(2.4)$ & .3 \\
\hline Vasopressin & 85 & $3(3.5)$ & 85 & $0(0)$ & .08 \\
\hline \multicolumn{6}{|l|}{ Blood products } \\
\hline Albumin (mL) & 54 & $500 \pm 240$ & 27 & $420 \pm 200$ & .15 \\
\hline Crystalloid (mL) & 84 & $2900 \pm 1000$ & 85 & $2900 \pm 850$ & .8 \\
\hline Any blood product $\ddagger$ & 85 & $21(25)$ & 85 & $21(25)$ & $>.9$ \\
\hline \multicolumn{6}{|l|}{ Glucose and insulin } \\
\hline Peak glucose $\left(\mathrm{mg} \cdot \mathrm{dL}^{-1}\right)$ & 84 & $240 \pm 41$ & 85 & $170 \pm 31$ & $<.0001$ \\
\hline Insulin & 85 & $70(82)$ & 85 & $39(46)$ & $<.0001$ \\
\hline \multicolumn{6}{|l|}{ Operative times (min) } \\
\hline Aortic clamp time, all approaches & 85 & $56 \pm 19$ & 85 & $44 \pm 14$ & $<.0001$ \\
\hline Full sternotomy & 8 & $69 \pm 27$ & 9 & $53 \pm 22$ & .16 \\
\hline Upper hemisternotomy & 77 & $54 \pm 17$ & 76 & $43 \pm 13$ & $<.0001$ \\
\hline CPB time, all approaches & 85 & $70 \pm 24$ & 85 & $56 \pm 18$ & $<.0001$ \\
\hline Full sternotomy & 8 & $87 \pm 37$ & 9 & $70 \pm 34$ & .3 \\
\hline Upper hemisternotomy & 77 & $68 \pm 21$ & 76 & $54 \pm 14$ & $<.0001$ \\
\hline Total OR time, all approaches & 85 & $310 \pm 61$ & 85 & $280 \pm 44$ & .009 \\
\hline Full sternotomy & 8 & $340 \pm 71$ & 9 & $300 \pm 46$ & .3 \\
\hline Upper hemisternotomy & 77 & $300 \pm 59$ & 76 & $280 \pm 44$ & .01 \\
\hline \multicolumn{6}{|l|}{ Intraoperative laboratory values } \\
\hline Peak potassium $\left(\mathrm{mmol} \cdot \mathrm{L}^{-1}\right)$ & 84 & $4.8 \pm 0.51$ & 85 & $4.6 \pm 0.53$ & .09 \\
\hline Nadir hematocrit $(\%)$ & 84 & $28 \pm 4.3$ & 85 & $28 \pm 3.9$ & .4 \\
\hline
\end{tabular}

(Tables 4 and 5). Longer ischemic times were associated with higher troponin $\mathrm{T}$ levels in both del Nido and Buckberg patients after mitral or aortic valve operations $(P<.0001$; Figure 2 and Table E4). Postoperative LVEF, adjusted for preoperative LVEF, was unaffected in both the del Nido and Buckberg groups after aortic valve $(P=.4)$ and mitral valve surgery $(P=.13)$ (Table E5).

\section{Inotropic Support and Other Secondary Outcomes}

Following aortic or mitral valve surgery, use of inotropic and vasopressive agents in the del Nido and Buckberg groups was similar (Tables 4 and 5). Prevalence of atrial fibrillation, volume of intraoperative resuscitative fluids, and transfusion requirements were also similar. Occurrence of permanent stroke, reoperation for bleeding/ tamponade, renal failure, and prolonged ( $>24$ hours) ventilation after either aortic or mitral valve surgery was similar in both cardioplegia groups (Table 6).

\section{Intraoperative Glucose Levels and Insulin-Drip Requirements}

Peak intraoperative glucose level was lower (172 \pm 31 vs $\left.236 \pm 41 \mathrm{mg} \cdot \mathrm{dL}^{-1}, P<.0001\right)$, as was the need for insulin drips $(46 \%$ vs $82 \%, P<.0001)$, after aortic valve operations performed with del Nido solution (Table 4). After mitral valve operations using del Nido solution, peak intraoperative glucose levels and insulin requirements were similarly lower $\left(184 \pm 37 \mathrm{vs} 247 \pm 60 \mathrm{mg} \cdot \mathrm{dL}^{-1}\right.$ and $50 \%$ vs $67 \%$, respectively, $P=.009$; Table 5).

\section{Operating Room Times}

For aortic valve operations overall, aortic clamp, CPB, and total operating room times were shorter with del Nido than with Buckberg solution (44 \pm 14 vs $56 \pm 19$ minutes, $56 \pm 18$ vs $70 \pm 24$ minutes, and $285 \pm 44$ vs $308 \pm 61$ minutes, respectively, $P<.0001$; Table 4). However, when evaluated by approach, only upper hemisternotomy cases were associated with shorter times when del Nido solution was used. In contrast, aortic clamp, $\mathrm{CPB}$, and operating room times were similar for mitral valve operations overall (Table 5). However, for those undergoing full sternotomy, they were shorter (48 \pm 14 vs 71 \pm 28 minutes, $P=.03 ; 67 \pm 15$ vs $96 \pm 33$ minutes, $P=.02$; and $280 \pm 32$ vs $320 \pm 69$ minutes, $P=.09$, respectively; Table 5) when del Nido solution was used, although total operating room time was similar. Only right 
TABLE 5. Management variables of matched patients undergoing mitral valve surgery

\begin{tabular}{|c|c|c|c|c|c|}
\hline \multirow[b]{2}{*}{ Variable } & \multicolumn{2}{|c|}{ Buckberg group $(\mathrm{n}=110)$} & \multicolumn{2}{|c|}{ del Nido group $(\mathrm{n}=110)$} & \multirow[b]{2}{*}{$P$ value } \\
\hline & $\mathbf{n}^{*}$ & No. $(\%)$ or mean \pm SD & $\mathbf{n}^{*}$ & No. $(\%)$ or mean \pm SD & \\
\hline \multicolumn{6}{|l|}{ Myocardial injury } \\
\hline Highest measured troponin $\mathrm{T}\left(\mathrm{ng} \cdot \mathrm{mL}^{-1}\right)$ & 110 & $0.21 / 0.40 / 1.03 \dagger$ & 107 & $0.19 / 0.37 / 0.76 \dagger$ & .2 \\
\hline \multicolumn{6}{|l|}{ Inotropic and vasoactive agents } \\
\hline Epinephrine & 110 & $14(13)$ & 110 & $21(19)$ & .2 \\
\hline Norepinephrine & 110 & $15(14)$ & 110 & $11(10)$ & .4 \\
\hline Milrinone & 110 & $1(0.91)$ & 110 & $1(0.91)$ & $>.9$ \\
\hline Vasopressin & 110 & $2(1.8)$ & 110 & $1(0.91)$ & 6 \\
\hline \multicolumn{6}{|l|}{ Blood products } \\
\hline Albumin (mL) & 57 & $440 \pm 179$ & 23 & $400 \pm 146$ & .5 \\
\hline Crystalloid (mL) & 109 & $2400 \pm 820$ & 110 & $2500 \pm 736$ & .18 \\
\hline Any blood product $\ddagger$ & 110 & $18(16)$ & 110 & $16(15)$ & .7 \\
\hline \multicolumn{6}{|l|}{ Glucose and insulin } \\
\hline Peak glucose $\left(\mathrm{mg} \cdot \mathrm{dL}^{-1}\right)$ & 108 & $250 \pm 60$ & 110 & $180 \pm 37$ & $<.0001$ \\
\hline Insulin & 110 & $74(67)$ & 110 & $55(50)$ & .009 \\
\hline \multicolumn{6}{|l|}{ Operative times (min) } \\
\hline Aortic clamp time, all approaches & 110 & $71 \pm 23$ & 110 & $67 \pm 22$ & .3 \\
\hline Full sternotomy & 9 & $71 \pm 28$ & 11 & $48 \pm 14$ & .03 \\
\hline Partial sternotomy & 30 & $74 \pm 29$ & 26 & $62 \pm 18$ & .3 \\
\hline Right thoracotomy & 33 & $61 \pm 14$ & 29 & $59 \pm 20$ & .12 \\
\hline Robotic & 38 & $76 \pm 22$ & 44 & $80 \pm 21$ & .13 \\
\hline CPB time, all approaches & 110 & $100 \pm 34$ & 110 & $98 \pm 33$ & .3 \\
\hline Full sternotomy & 9 & $96 \pm 33$ & 11 & $67 \pm 15$ & .02 \\
\hline Partial sternotomy & 30 & $98 \pm 35$ & 26 & $85 \pm 19$ & .3 \\
\hline Right thoracotomy & 33 & $91 \pm 20$ & 29 & $79 \pm 23$ & .008 \\
\hline Robotic & 38 & $112 \pm 40$ & 44 & $125 \pm 29$ & .03 \\
\hline Total OR time, all approaches & 110 & $342 \pm 80$ & 110 & $335 \pm 60$ & .8 \\
\hline Full sternotomy & 9 & $318 \pm 69$ & 11 & $280 \pm 32$ & .09 \\
\hline Partial sternotomy & 30 & $351 \pm 85$ & 26 & $341 \pm 66$ & .8 \\
\hline Right thoracotomy & 33 & $345 \pm 104$ & 29 & $316 \pm 48$ & .3 \\
\hline Robotic & 38 & $337 \pm 49$ & 44 & $359 \pm 56$ & .08 \\
\hline \multicolumn{6}{|l|}{ Intraoperative laboratory values } \\
\hline Peak potassium $\left(\mathrm{mmol} \cdot \mathrm{L}^{-1}\right)$ & 108 & $5.01 \pm 0.65$ & 110 & $4.9 \pm 0.54$ & .16 \\
\hline Nadir hematocrit $(\%)$ & 108 & $29 \pm 4.3$ & 110 & $29 \pm 4.4$ & .9 \\
\hline
\end{tabular}

thoracotomy $\mathrm{CPB}$ times were statistically significantly lower in the del Nido group ( $79 \pm 23$ vs $91 \pm 20$ minutes, $P=.008)$.

\section{DISCUSSION \\ Principal Findings}

This study demonstrates no disadvantages to using del Nido solution in primary isolated adult aortic or mitral valve surgery. Measures of myocardial injury, such as troponin $\mathrm{T}$ levels, postoperative LVEF, and postoperative inotropic/ pressor support were similar to those of patients for whom Buckberg solution was used.

Use of del Nido solution has several advantages. The crystalloid component of del Nido solution is not glucose-based (unlike Buckberg solution), and patients receiving it had fewer blood glucose perturbations, and less need for postoperative insulin drips. The groups were well matched with regard to presence or absence of diabetes, as well as preoperative glucose levels. However, more patients who had Buckberg solution required insulin drips afterward than did those with a history of diabetes. Specifically, only $46 \%$ of aortic valve patients receiving Buckberg cardioplegia had a history of diabetes, but $82 \%$ were placed on insulin drips.

Operative times were shorter with certain operative approaches. The reduction in time may be due to fewer interruptions of the surgical repair and perhaps to a decreased need for coronary sinus cannulation (in patients without important aortic regurgitation, only antegrade cardioplegia was used in del Nido cases). We speculate, however, that some of these differences between operative approaches (eg, full sternotomy or right thoracotomy) were surgeonspecific.

An additional advantage of using del Nido solution is its lower cost. Although we did not formally collect cost data in this study, multiple areas of potential cost savings are 

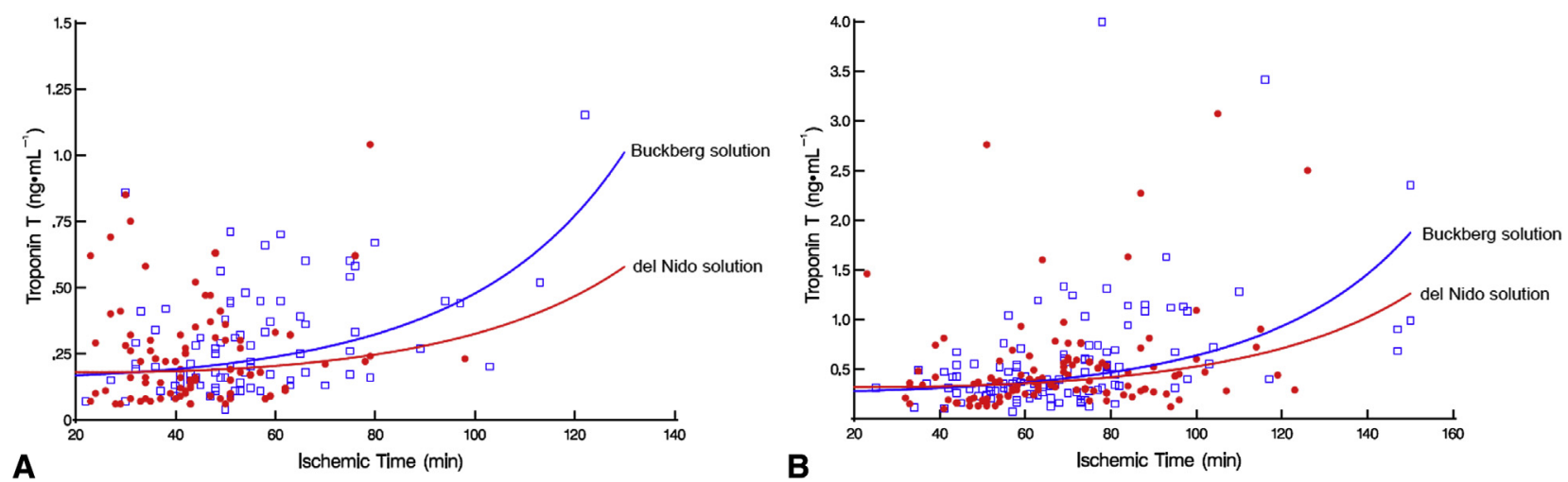

FIGURE 2. Relationship of troponin T level to myocardial ischemic time. Filled circles represent values for del Nido patients; open squares represent values for Buckberg patients. Solid lines are regression estimates (Table E4). A, Patients undergoing primary isolated aortic valve operations. B, Patients undergoing primary isolated mitral valve operations.

associated with this form of cardioplegia. At our institution, del Nido solution costs approximately $\$ 29$ per dose; Buckberg solution costs approximately $\$ 75$ per dose. Assuming 1 dose of del Nido solution per case, and at least 1 maintenance dose in a Buckberg solution case, the cardioplegia costs associated with del Nido solution are about \$29, versus \$225 for Buckberg solution (a savings of approximately $\$ 196$ ).

When retrograde cardioplegia is not used, additional savings are possible. For instance, the percutaneous retrograde cannula we use in robotic cases costs roughly $\$ 1000$, whereas in open surgery, such equipment costs about $\$ 30$, resulting in an overall savings of at least $\$ 1190$ per robotic case and $\$ 220$ per open case. However, equipment cost savings may vary among institutions, depending on the retrograde cannula used. Additional areas for savings include decreased operating room time and costs associated with insulin drips. In an era when healthcare costs are increasingly scrutinized, and maximal efficiency has become a vital concern, these differences have important implications.

\section{Clinical Implications}

Our adoption of del Nido solution has been intentionally cautious. Two critical keys to the success of "oneshot" cardioplegia are adequate delivery and excellent venous return. Thus, we have elected not to use del Nido solution in patients with important coronary artery disease, in an effort to avoid inhomogeneous or incomplete delivery, and this study cannot speak to its proper use in such patients. Impaired venous return tends to rewarm the heart (increasing myocardial metabolic demand), and the attendant increased venous back pressure encourages cardioplegia washout.

Patients in this study were in good overall health, with preserved left ventricular systolic function, and they underwent procedures with aortic clamp times that rarely exceeded 90 minutes. This investigation does not allow us to comment reliably on optimal redosing strategies or the safety of del Nido solution in sicker patients (eg, those with depressed LVEF), or on those undergoing operations with longer aortic clamp times.

TABLE 6. Postoperative complications in matched patients undergoing aortic or mitral valve surgery

\begin{tabular}{|c|c|c|c|}
\hline & $\underline{\text { Buckberg group }(\mathrm{n}=\mathbf{8 5})}$ & del Nido group $(\mathbf{n}=85)$ & \\
\hline Complications & No. $(\%)$ & No. $(\%)$ & $P$ value \\
\hline \multicolumn{4}{|l|}{ Aortic valve surgery $(\mathrm{n}=85)$} \\
\hline Hospital death & $0(0)$ & $0(0)$ & - \\
\hline Permanent stroke & $0(0)$ & $1(1.2)$ & .3 \\
\hline Renal failure & $1(1.2)$ & $2(2.4)$ & .6 \\
\hline Reoperation for bleeding/tamponade & $3(3.5)$ & $0(0)$ & .08 \\
\hline Atrial fibrillation & $27(32)$ & $30(35)$ & .6 \\
\hline \multicolumn{4}{|l|}{ Mitral valve surgery $(\mathrm{n}=110)$} \\
\hline Hospital death & $0(0)$ & $0(0)$ & - \\
\hline Permanent stroke & $1(0.91)$ & $1(0.91)$ & $>.9$ \\
\hline Renal failure & $0(0)$ & $0(0)$ & - \\
\hline Prolonged ventilation $(>24 \mathrm{~h})$ & $0(0)$ & $1(0.91)$ & .3 \\
\hline Reoperation for bleeding/tamponade & $0(0)$ & $1(0.91)$ & .3 \\
\hline Atrial fibrillation & $32(29)$ & $35(32)$ & .7 \\
\hline
\end{tabular}




\section{Limitations}

This is a single-institution study, which limits its generalizability. We did not capture surgeon-specific details, such as adjuncts to myocardial protection (eg, systemic/topical cooling or use of a myocardial temperature probe to assess adequacy of delivery). Also not captured were perfusionistspecific maneuvers, such as intraoperative hemoconcentration, that may have played a role in avoiding hemodilution in cases using del Nido solution (which has a 4:1 crystalloid:blood ratio compared with the 1:4 ratio of Buckberg solution). Similarly, the potential effects on procedural costs associated with hemoconcentration (at a rough cost of \$70, if performed) were not captured. Finally, patients were not matched for operative year; this was necessary to provide an adequate pool for propensity matching, because use of del Nido solution in isolated valve surgery quickly took hold after its introduction at our institution.

\section{CONCLUSIONS}

del Nido solution seems to be safe for use in adult primary isolated aortic or mitral valve operations. It has the advantages of decreased potential for surgical interruption, lower perturbations in intraoperative blood glucose levels, less need for postoperative insulin drips, decreased surgical times in certain surgical approaches, and lower costs. Caution is still warranted in adopting this form of cardioplegia, and further study is required to establish its indications and optimal use.

S.M. thanks Dr Pedro del Nido for initiating her interest in del Nido cardioplegia and for his and Greg Matte's (chief perfusionist at Children's Hospital Boston) insights and guidance during the institution of its use at Cleveland Clinic. The authors are grateful to the surgeons (particularly Drs Michael Argenziano and Craig Smith) and perfusionists (particularly Linda Mongero) of New York Presbyterian Hospital-Columbia for allowing us to observe their use of del Nido solution and for graciously sharing experiences and insights with us. S.M. thanks Patrick Grady and the entire perfusion team at Cleveland Clinic for their support in instituting this novel type of cardioplegia. Special thanks also go to Catherine Torma, CCP, and Annmarie Fatula, CCP, for their intraoperative data collection and management thereof.

\section{References}

1. Follette DM, Steed DL, Foglia R, Fey K, Buckberg GD. Advantages of intermittent blood cardioplegia over intermittent ischemia during prolonged hypothermic aortic clamping. Circulation. 1978;58:I200-9.

2. Follette DM, Mulder DG, Maloney JV, Buckberg GD. Advantages of blood cardioplegia over continuous coronary perfusion or intermittent ischemia. Experimental and clinical study. J Thorac Cardiovasc Surg. 1978;76:604-19.

3. Follette DM, Fey K, Buckberg GD, Helly JJ Jr, Steed DL, Foglia RP, et al. Reducing postischemic damage by temporary modification of reperfusate calcium, potassium, pH, and osmolarity. J Thorac Cardiovasc Surg. 1981;82:221-38.

4. Matte GS, del Nido PJ. History and use of del Nido cardioplegia solution at Boston's Children's Hospital. J Extra Corpor Technol. 2012;44:98-103.
5. Govindapillai A, Hua R, Rose R, Friesen CH, O'Blenes SB. Protecting the aged heart during cardiac surgery: use of del Nido cardioplegia provides superior functional recovery in isolated hearts. J Thorac Cardiovasc Surg. 2013;146:940-8.

6. O'Blenes SB, Friesen CH, Ali A, Howlett S. Protecting the aged heart during cardiac surgery: the potential benefits of del Nido cardioplegia. J Thorac Cardiovasc Surg. 2011;141:762-70.

7. Teoh KH, Christakis GT, Weisel RD, Fremes SE, Mickle DA, Romaschin AD, et al. Accelerated myocardial metabolic recovery with terminal warm blood cardioplegia. J Thorac Cardiovasc Surg. 1986;91:888-95.

8. Rubin DB. The design versus the analysis of observational studies for causal effects: parallels with the design of randomized trials. Stat Med. 2007;26:20-36.

9. Breiman L. Bagging predictors. Machine Learn. 1996;24:123-40.

10. Sauerbrei W, Schumacher M. A bootstrap resampling procedure for model building: application to the Cox regression model. Stat Med. 1992;11:2093-109.

11. Bergstralh EJ, Konsanke JL. Computerized Matching of Cases to Controls. Technical Rep. No. 56. Rochester, Minn: Dept Health Science Research, Mayo Clinic; 1995.

\section{Discussion}

Dr Mick. Good morning. I would like to thank the Association for the privilege of presenting these data to you today. My coauthors and I have no relevant disclosures. del Nido solution (DNS) is a 1-shot cardioplegic good for up to 3 hours. It is a potassium-based cardioplegic, with a concurrent lidocaine sodium-channel blockade, and contains additional additives for free-radical scavenging, calcium-channel blockage, and $\mathrm{pH}$ buffering.

DNS has been used at Children's Hospital, Boston, exclusively for many years. Most institutions consider DNS to be for children only, but in Boston it is used in both pediatric and adult operations. This practice has gotten the attention of many adult cardiac surgeons, and there is increasing interest in its use in adults. Indeed, it has become the sole method of cardioplegia at Columbia Presbyterian Hospital in New York over the past several years. However, there are no published human data on the use of DNS in adults.

At our institution, we have used Buckberg solution (BCS) to induce cardioplegia for decades. Here is a comparison of BCS and DNS, side by side, to show some important differences. First, BCS is 1 part crystalloid to 4 parts blood, whereas DNS is 4 parts crystalloid to 1 part blood, making the final product much more crystalloid-based. The base crystalloid solution in BCS is glucose-based. It is D5 one quarter normal saline, whereas DNS is not. BCS is given every 15 minutes, whereas DNS lasts for up to 3 hours. Both contain potassium to induce depolarized diastolic myocardial arrest, and both contain additives that confer additional benefits. At our institution, BCS is generally given on an antegrade and retrograde basis. DNS administration is antegrade only, unless significant aortic regurgitation is present.

We first became interested in using DNS for cardioplegia in the context of minimally invasive valve surgery. Although BCS for cardioplegia has been a staple at our institution, it does require redosing every 15 to 20 minutes, which may cause interruptions in the surgical flow, and in the level of exposure in these operations, especially in cases using robotics. In addition, it is often delivered partially in retrograde fashion, and gaining access to the coronary sinus and being minimally invasive can be a little bit more challenging. So, in working to 
simplify these operations, we introduced use of DNS for cardioplegia. Since that time, we have gradually expanded its use to include other routine cases in which there is no coronary artery disease.

Our hypothesis was that use of DNS to induce cardioplegia offers equally safe myocardial protection compared with BCS. We conducted a retrospective study examining all patients undergoing isolated valve operations at our institution. We excluded patients, as I have mentioned, with significant coronary artery disease, as that can influence the distribution of cardioplegia, and may have an impact on outcomes.

Of the more than 2400 patients we identified, most were given BCS, and just over 200 were given DNS. In order to more accurately compare the effects of the 2 solutions, the patients were $1: 1$ propensity matched. As you can see, the patients were well matched with respect to ejection fraction $(\mathrm{EF})$, preoperative hematocrit, creatinine clearance, presence of diabetes, and degree of aortic regurgitation with the yellow triangles representing the characteristics before the match, and the red squares representing the patients after propensity matching.

The first question we wanted to answer is whether DNS for cardioplegia is safe in adults undergoing isolated valve surgery. There was no in-hospital death in either group of the propensity-matched patients. In this cumulative distribution plot, we can see that in aortic valve surgery, the troponin levels after use of DNS are shifted slightly to the left, indicating lower troponin levels, although this did not quite reach statistical significance. A similar leftward shift is seen in the patients undergoing mitral operations, but in contrast to the aortic patients, the tails are longer, indicating more peak troponin levels, which were higher in both groups. This finding is not surprising, as in mitral surgery, we are cutting the myocardium, whereas this is not done in routine aortic valve operations.

There was no difference in the percentage of patients requiring inotropes, or in the volume of albumin or crystalloid resuscitation given to these patients in the operating room. Even though DNS is more heavily crystalloid-based, and BCS is given more frequently, there was no difference in regard to on-pump nadir hematocrit or the need for transfusion. There was also no difference in postoperative atrial fibrillation.

So, it looks like use of DNS is safe in this population, but are there any benefits? Peak serum glucose levels during surgery with DNS are significantly lower, likely owing to the nonglucose base of this cardioplegic. This difference translated into fewer patients in the DNS group requiring insulin drips postoperatively. Interestingly, the percentage of patients requiring insulin drips following surgery with BCS was actually much greater than the percentage in that group who were diabetic, leading us to wonder if BCS is causing more iatrogenic hyperglycemia, even in nondiabetics. In the aortic group, cross-clamp times, as well as bypass times, and total time in the operating room, were significantly shorter with DNS. In the mitral group, the selected times were different, but the difference did not reach significance.

There are cost savings. DNS is about $\$ 30$ per bag, compared with $\$ 75$ for BCS, translating into at least $\$ 200$ more per operation for BCS, and that is assuming only 1 cardioplegia maintenance dose is given for BCS patients. There are other cost savings as well. For instance, with DNS, a retrograde cannula or its tubing may not be needed. So in these cases, the overall operation costs far less: \$220 less per open case, and more than $\$ 1000$ less per case involving robotics, mainly because of the cost of the cannula in those cases. Other areas of savings that are not factored into these numbers are the operative time savings, and the costs associated with insulin drips.

Our adoption of DNS has been intentionally cautious. It is very important to bear in mind that the success of 1-shot cardioplegia depends on adequate delivery the first time. We do not use DNS in patients with coronary artery disease. In addition, the success of 1-shot cardioplegia relies on excellent venous drainage throughout the procedure. Without excellent venous drainage, you can run into the problem of the heart rewarming, which increases the myocardial metabolic demand; also, the venous back pressure has a tendency to negate the cardioplegic effect.

As far as the limitations of our study - these were, by and large, healthy patients, needing only short cross-clamp times, and we were not able to capture surgeon-specific adjuncts to myocardial protection such as systemic or topical cooling, or the use of temperature probes to assess cardioplegia delivery. Additionally, perfusionist-specific maneuvers were not captured; for instance, our perfusion group tends to hemoconcentrate these cases as a matter of course, and that was not captured.

But in conclusion, from our retrospective review of propensitymatched adult patients undergoing isolated valve surgery, use of DNS for cardioplegia seems to be safe, more efficient, and less expensive. Thank you again for the opportunity to present these data.

Dr Richard Shemin (Los Angeles, Calif). I want to thank the Association for the opportunity to discuss this excellent paper. I have no disclosures except for perhaps that Dr Buckberg is one of our faculty at UCLA (University of California, Los Angeles). So, you are lucky he is not standing here instead of me, as he may take some of this personally. Excellent presentation-very clear, and thank you for your paper, which is also excellent.

So, your study is really of low risk, good EF, aortic valve and mitral valve replacement, predominantly with minimal-access approaches, using what I think is a single-dose, antegrade, cold, DNS. Then you did your propensity matching to what you call "Buckberg cardioplegia." Your primary endpoint was peak troponin, and you saw no statistical differences. In your paper, you additionally had data about the use of postoperative inotropes, and it is important to mention that you saw no difference in the use of inotropes in the postoperative period in the aortic versus mitral valve patients. You did see some reduction in some of the operative times, blood sugars, insulin drips, and costs.

Many of us have kind of lived through all the decades of cardioplegia development, from the research lab, through thousands of papers, to the clinic at this point in time, and obviously, a BCS cardioplegia style has been adopted by almost all cardiac surgeons for adult patients. We know that we can get good, reliable protection for several hours with hypertrophy myocardium, scheming myocardium, low EFs, and patients with multiple coronary obstructions, because it is not just the cardioplegia solution alone; it is how we deliver it, antegrade 
and retrograde, in addition to the concepts of induction and maintenance every 20 minutes, and in particular, reperfusion. So, we are all intrigued by the simplicity of a single dose, 3 hours of protection, and whether it can really be as good. So, clearly you have shown in your paper that it is probably as good, at least, in this subset of patients. So, let me ask you a series of questions to help us better understand things.

Obviously, there is a Cleveland Clinic style of using BCS for cardioplegia. I assume, as you have described, it is antegrade, retrograde every 20 minutes. Tell me a little bit about your reperfusion techniques, and whether they are consistent among all the surgeons, because clearly that is what you are comparing as your control group.

Dr Mick. Right. As far as the reperfusion technique, I would say that about $80 \%$ of surgeons give hot shot cardioplegia as the final dose, antegrade and retrograde.

Dr Shemin. Okay. Thank you. The other thing that was interesting in your paper is that in the data on the use of postoperative inotropes, I was surprised to see in this low-risk group of normal EFs that in somewhere around $15 \%$ to $18 \%$ in the control group, Buckberg cardioplegia-

Dr Mick. Both groups.

Dr Shemin. - required inotrope support in their early postoperative period. So, the question that comes to mind is: Was the use of BCS to induce cardioplegia truly optimal in your control group?

Dr Mick. That is a good question. We actually looked at the dose of inotropes in both groups. Our most common inotrope is epinephrine. It was given in a very small dose of $2 \mathrm{mcg}$ per minute, so it was not so much a "requirement," but rather sort of a little booster postbypass. They were very small doses of inotropes. Our anesthesiologists tend to be a bit aggressive with this type of thing.

Dr Shemin. So, do you have any echo data for us, pre- and postoperatively, looking at septal motion, septal wall motion abnormalities, or other things that we would clearly look at as far as the quality of protection?

Dr Mick. No. I did not look at echo data in this retrospective review. We are planning a prospective analysis on this subject and will likely focus on the echo data in that study.
Dr Shemin. So, in your presentation, you say this is a single dose for 3 hours. Did the clinical experience show any return of electrical activity? If it did, did you give it antegrade or retrograde?

Dr Mick. Unfortunately, I do not have data on return of electrical activity with DNS. The average overall dose of DNS for cardioplegia in this group of patients was about 1 liter, but we are looking into the cases in which redosing occurred.

Dr Shemin. You know, so many people actually believe that the reperfusion after ischemia is an important part of the overall strategy, so in the DNS group, was there any type of reperfusion? Or did you just release-

Dr Mick. No. There is no hot shot or reperfusion dose with DNS; you just release the clamp. Just as a point of interest, the patients receiving DNS for cardioplegia generally return from arrest to a sinus rhythm, and they only require defibrillation about $6 \%$ of the time. In thinking about this, one of the discussions among the surgeons in our group was that perhaps the fact that we are seeing a slightly lower troponin value in these patients is a function of their not having been defibrillated after surgery.

Dr Shemin. My final question is, given that you used propensity matching to do the study, obviously the main bias is who got the DNS. So, from the paper, I can tell that they were individuals with good EFs, having routine operations, with cross-clamp time of less than maybe 90 minutes. Are there other characteristics that we should know about, so that we do not go home and apply these data inappropriately to our patients?

Dr Mick. You are right that the patients we generally use DNS on are individuals with preserved EFs, undergoing elective procedures. We also consider the degree of aortic regurgitation the complexity of the procedure, and of course, any undiagnosed or even moderate coronary disease. Those are the main things.

Dr Shemin. Well, thank you again for an excellent presentation, and a very timely article. I think it has peaked all of our interests, and maybe we have got to get our colleagues from Columbia, if this is their standard of care, to start publishing-

Dr Mick. Thank you very much.

Dr Shemin. - and sharing some of those data with us.

Dr Mick. Thank you very much. 


\section{APPENDIX E1. REDOSING}

We reviewed every case in which the total dose of del Nido solution was larger than 1 dose per aortic clamp period. Among the 195 matched del Nido cases, 21 were redosing cases. Two were aortic valve cases in which a small initial antegrade dose was not sufficient for arrest, so an aortotomy was made, and an additional dose was administered directly down the coronary ostia. One case involved a patient who fibrillated after aortic clamp removal and was rearrested briefly after electrical defibrillation failed. Intraoperative redosing was highly surgeon-dependent and generally involved a partial (200-500 cc) additional dose of del Nido solution after 45 to 90 minutes. This occurred in 3 aortic valve cases $(3.5 \%)$ and 15 mitral valve cases $(14 \%)$.

\section{APPENDIX E2. VARIABLES CONSIDERED IN PROPENSITY ANALYSES}

\section{Demography}

Age* (years); sex*; race* (black, white, other); height* $(\mathrm{cm})$; weight $(\mathrm{kg})$; body surface area $\left(\mathrm{m}^{2}\right)$; body mass index* $\left(\mathrm{kg} \cdot \mathrm{m}^{-2}\right)$.

\section{Presentation}

New York Heart Association functional class (I-IV)*; prior stroke; prior myocardial infarction.*

\section{Cardiac Comorbidity}

Preoperative atrial fibrillation*; heart failure*; coronary artery disease* ${ }^{*}$ (number of systems with $\geq 50 \%$ stenosis).

\section{Noncardiac Comorbidity}

Preoperative glucose*; pharmacologically treated diabetes*; hypertension*; peripheral arterial disease*; history of smoking*; chronic obstructive pulmonary disease; renal failure requiring dialysis; blood urea nitrogen* $\left(\mathrm{mg} \cdot \mathrm{dL}^{-1}\right)$; creatinine* $\left(\mathrm{mg} \cdot \mathrm{dL}^{-1}\right)$; bilirubin* $\left(\mathrm{mg} \cdot \mathrm{dL}^{-1}\right)$; cholesterol (total, high-density lipoprotein* $\left[\mathrm{mg} \cdot \mathrm{dL}^{-1}\right]$; low-density lipoprotein $\left.\left[\mathrm{mg} \cdot \mathrm{dL}^{-1}\right]\right)$; triglycerides $\left(\mathrm{mg} \cdot \mathrm{dL}^{-1}\right)^{*}$; hematocrit $(\%)$.

\section{Echocardiography Data (Preoperative)}

Aortic valve regurgitation grade*; mitral valve regurgitation grade*; tricuspid valve regurgitation grade*; aortic valve stenosis*; mitral valve stenosis*; left ventricular (LV) ejection fraction* $(\%)$; LV internal diameter in diastole $(\mathrm{cm})$; LV internal end-systolic diameter $(\mathrm{cm})$; LV enddiastolic volume $(\mathrm{mL})$; LV end-systolic volume; LV mass (g); LA (left atrial) diameter $(\mathrm{cm})$; LA volume* $(\mathrm{mL})$; posterior wall thickness* $(\mathrm{cm})$; aortic valve area* $\left(\mathrm{cm}^{2}\right)$.

Valve Etiology

Rheumatic*; degeneration $\dagger$; endocarditis. $\dagger$

\section{Procedural}

Aortic or mitral valve replacement*; incision (full sternotomy, minimally invasive*; port $\dagger$ )

* In final propensity models.

$\dagger$ In mitral valve propensity model only. 

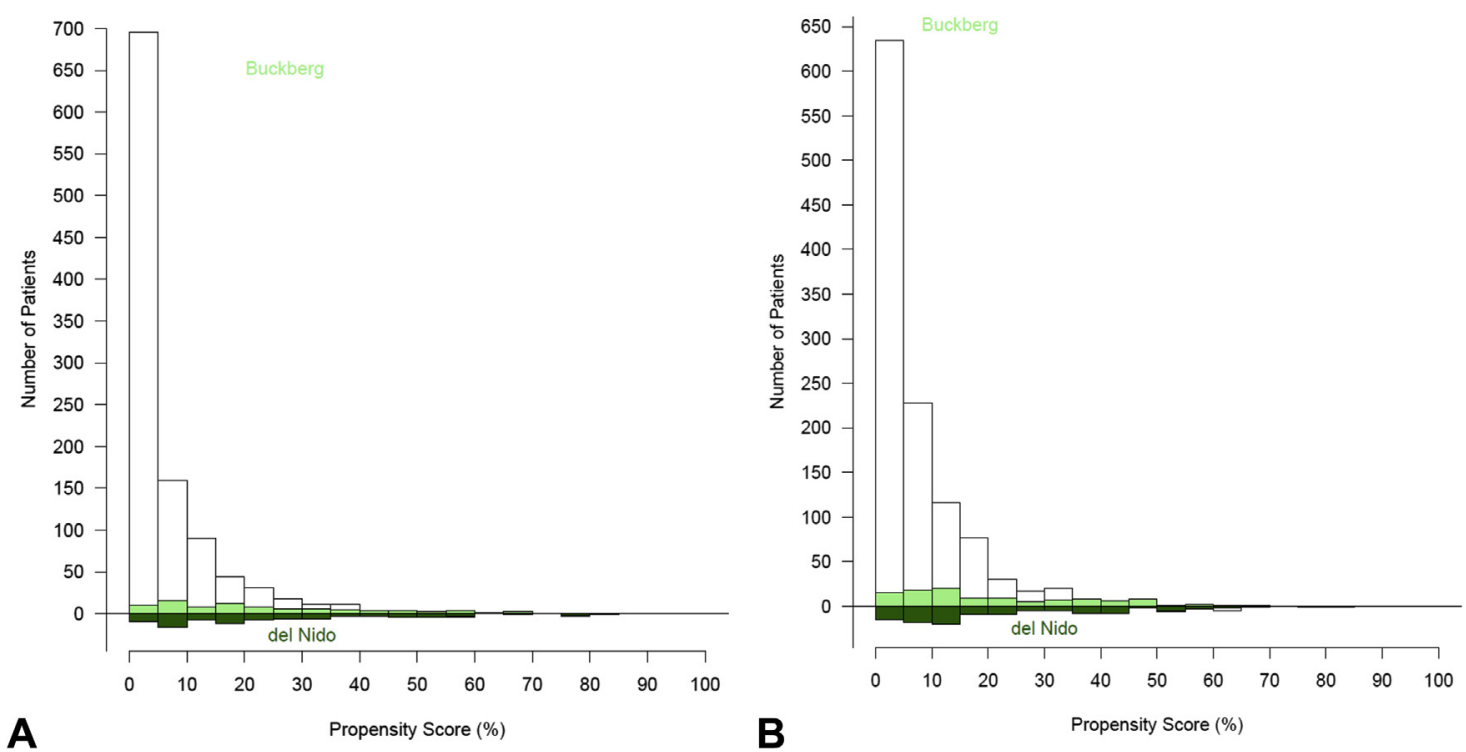

FIGURE E1. Mirrored histogram of distribution of propensity scores. Darkened areas represent matched patient pairs: (A) isolated aortic valve surgery; (B) isolated mitral valve surgery.
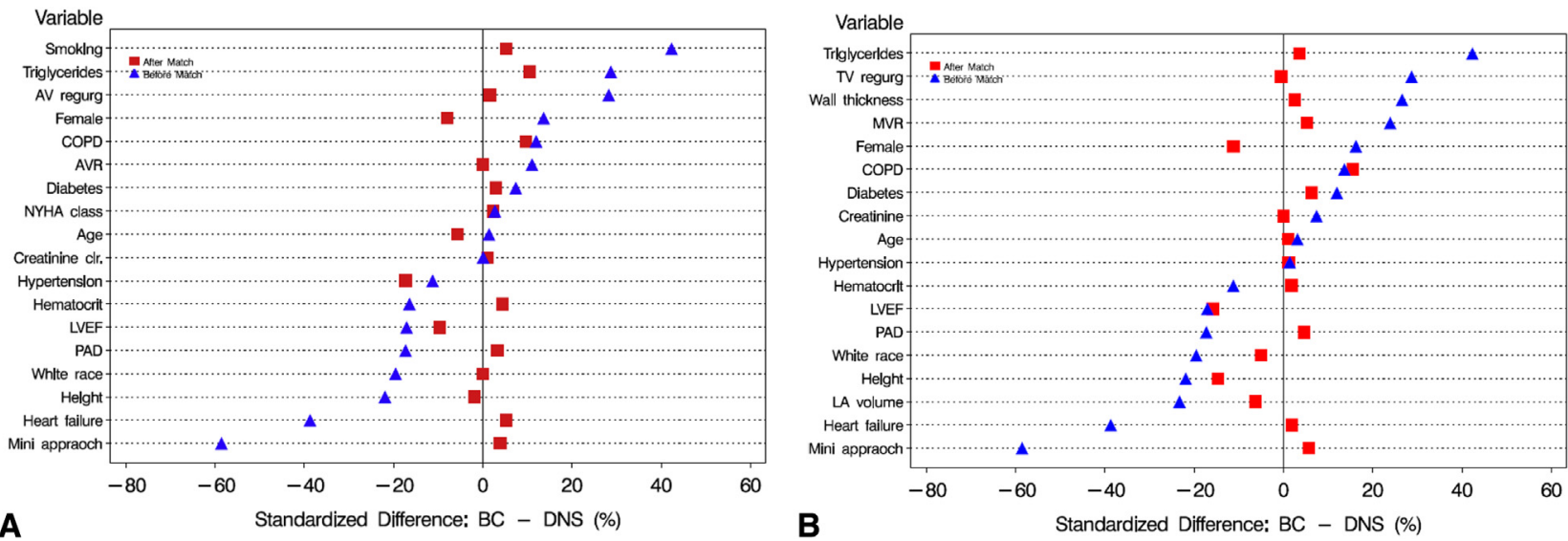

FIGURE E2. Propensity-score matching for del Nido versus Buckberg solution in adult isolated valve surgery. A, Covariable balance for selected variables before (triangles) and after (squares) propensity matching, expressed as standardized difference: aortic valve surgery. B, Covariable balance for selected variables before (triangles) and after (squares) propensity matching, expressed as standardized difference: mitral valve surgery. AV, Aortic valve; $C O P D$, chronic obstructive pulmonary disease; $A V R$, aortic valve replacement; $N Y H A$, New York Heart Association; $C l r$, clearance; $L V E F$, left ventricular ejection fraction; $P A D$, peripheral arterial disease; $B C$, Buckberg solution; DNS, del Nido solution; TV regurg, tricuspid valve regurgitation; $M V R$, mitral valve replacement; $L A$, left atrial. 
TABLE E1. Characteristics and operative details of patients undergoing aortic valve surgery: Before matching

\begin{tabular}{|c|c|c|c|c|c|}
\hline \multirow[b]{2}{*}{ Variable } & \multicolumn{2}{|c|}{ Buckberg group $(n=1074)$} & \multicolumn{2}{|c|}{ del Nido group $(n=89)$} & \multirow[b]{2}{*}{$P$ value } \\
\hline & $\mathbf{n}^{*}$ & No. $(\%)$ or mean \pm SD & $\mathbf{n}^{*}$ & No. $(\%)$ or mean \pm SD & \\
\hline \multicolumn{6}{|l|}{ Demographics } \\
\hline Women & 1074 & $440(41)$ & 89 & $28(31)$ & .08 \\
\hline Age (y) & 1074 & $66 \pm 15$ & 89 & $69 \pm 14$ & .17 \\
\hline Body mass index $\left(\mathrm{kg} \cdot \mathrm{m}^{-2}\right)$ & 1073 & $30 \pm 7.4$ & 89 & $29 \pm 6.6$ & .3 \\
\hline NYHA functional class & 875 & & 89 & & 6 \\
\hline I & & $279(32)$ & & $23(26)$ & \\
\hline II & & $419(48)$ & & $44(49)$ & \\
\hline III & & $158(18)$ & & $20(22)$ & \\
\hline IV & & $19(2.2)$ & & $2(2.2)$ & \\
\hline \multicolumn{6}{|l|}{ Aortic valve pathophysiology } \\
\hline Aortic valve area $\left(\mathrm{cm}^{2}\right)$ & 812 & $0.74 \pm 0.29$ & 83 & $0.81 \pm 0.50$ & .6 \\
\hline Mean aortic valve gradient $(\mathrm{mm} \mathrm{Hg})$ & 929 & $31 / 46 / 65 \dagger$ & 86 & $34 / 51 / 63 \dagger$ & .4 \\
\hline Peak aortic valve gradient $(\mathrm{mm} \mathrm{Hg})$ & 941 & $80 \pm 30$ & 86 & $83 \pm 28$ & .2 \\
\hline \multicolumn{6}{|l|}{ Cardiovascular comorbidity } \\
\hline Calculated LV relative wall thickness $(\mathrm{cm})$ & 981 & $0.54 \pm 0.17$ & 86 & $0.54 \pm 0.14$ & .5 \\
\hline LV ejection fraction $(\%)$ & 1060 & $57 \pm 9.0$ & 88 & $60 \pm 10$ & .04 \\
\hline Calculated LV mass (g) & 980 & $250 \pm 95$ & 86 & $230 \pm 77$ & .2 \\
\hline Atrial fibrillation or flutter & 1066 & $59(5.5)$ & 89 & $10(11)$ & .03 \\
\hline Peripheral arterial disease & 1074 & $73(6.8)$ & 89 & $15(17)$ & .0006 \\
\hline Hypertension & 1074 & $850(79)$ & 89 & $84(94)$ & .0005 \\
\hline \multicolumn{6}{|l|}{ Noncardiac comorbidity } \\
\hline \multicolumn{6}{|l|}{ Diabetes } \\
\hline Pharmacologically treated & 1073 & $234(22)$ & 89 & $20(22)$ & .9 \\
\hline Insulin treated & 1071 & $72(6.7)$ & 89 & $8(9.0)$ & .4 \\
\hline Non-insulin treated & 1071 & $177(17)$ & 89 & $14(16)$ & .8 \\
\hline Potassium $\left(\mathrm{mmol} \cdot \mathrm{L}^{-1}\right)$ & 1073 & $4.2 \pm 0.62$ & 89 & $4.1 \pm 0.56$ & .13 \\
\hline Glucose $\left(\mathrm{mg} \cdot \mathrm{dL}^{-1}\right)$ & 1074 & $102 \pm 27$ & 89 & $108 \pm 39$ & .2 \\
\hline Creatinine $\left(\mathrm{mg} \cdot \mathrm{dL}^{-1}\right)$ & 1074 & $1.04 \pm 0.67$ & 89 & $0.98 \pm 0.26$ & .6 \\
\hline Cockcroft-Gault creatinine clearance & 1073 & $91 \pm 39$ & 89 & $87 \pm 34$ & .4 \\
\hline Hematocrit $(\%)$ & 1074 & $38 \pm 5.3$ & 89 & $39 \pm 4.9$ & .16 \\
\hline \multicolumn{6}{|l|}{ Operative details } \\
\hline \multicolumn{6}{|l|}{ Aortic valve surgery } \\
\hline Repair & 1074 & $63(5.9)$ & 89 & $7(7.9)$ & .5 \\
\hline Replacement & 1074 & $1011(94)$ & 89 & $82(92)$ & .5 \\
\hline \multicolumn{6}{|l|}{ Incision/approach } \\
\hline Full sternotomy & 1054 & 355 (34) & 89 & $9(10)$ & $<.0001$ \\
\hline Hemisternotomy & 1054 & $699(66)$ & 89 & $80(90)$ & $<.0001$ \\
\hline Year of operation & 1074 & & 89 & & $<.0001$ \\
\hline 2010 & & $331(31)$ & & $0(0)$ & \\
\hline 2011 & & 308 (29) & & $0(0)$ & \\
\hline 2012 & & 312 (29) & & $8(9.0)$ & \\
\hline 2013 & & $123(11)$ & & $81(91)$ & \\
\hline
\end{tabular}

$S D$, Standard deviation; NYHA, New York Heart Association; $L V$, left ventricular. *Patients with data available. $\dagger$ Median (15th, 85 th) percentiles. 
TABLE E2. Characteristics and operative details of patients undergoing mitral valve surgery: Before matching

\begin{tabular}{|c|c|c|c|c|c|}
\hline \multirow[b]{2}{*}{ Variable } & \multicolumn{2}{|c|}{ Buckberg group $(n=1150)$} & \multicolumn{2}{|c|}{ del Nido group $(n=116)$} & \multirow[b]{2}{*}{$P$ value } \\
\hline & $\mathbf{n}^{*}$ & No. $(\%)$ or mean \pm SD & & No. $(\%)$ or mean \pm SD & \\
\hline \multicolumn{6}{|l|}{ Demographics } \\
\hline Women & 1150 & $398(35)$ & 116 & $36(31)$ & .4 \\
\hline Age (y) & 1150 & $57 \pm 12$ & 116 & $56 \pm 11$ & .2 \\
\hline Body mass index $\left(\mathrm{kg} \cdot \mathrm{m}^{-2}\right)$ & 1149 & $26 \pm 4.9$ & 116 & $25 \pm 3.4$ & .3 \\
\hline NYHA functional class & 904 & & 116 & & .01 \\
\hline I & & $401(44)$ & & $51(44)$ & \\
\hline II & & $385(43)$ & & $61(53)$ & \\
\hline III & & $109(12)$ & & $3(2.6)$ & \\
\hline IV & & $9(1.0)$ & & $1(0.86)$ & \\
\hline \multicolumn{6}{|l|}{ Mitral valve pathophysiology } \\
\hline Mitral regurgitation grade & 1150 & & 116 & & .7 \\
\hline $1+$ & & $21(1.7)$ & & $1(0.86)$ & \\
\hline $2+$ & & $41(3.6)$ & & $2(1.7)$ & \\
\hline $3+$ & & $249(22)$ & & $23(20)$ & \\
\hline $4+$ & & $836(73)$ & & $90(78)$ & \\
\hline Mitral stenosis & 1150 & $31(2.7)$ & 116 & $2(1.7)$ & .5 \\
\hline \multicolumn{6}{|l|}{ Cardiovascular comorbidity } \\
\hline LV ejection fraction $(\%)$ & 1131 & $59 \pm 6.1$ & 114 & $60 \pm 5.4$ & .11 \\
\hline Calculated LV mass ( $\mathrm{g}$ ) & 1044 & $240 \pm 80$ & 108 & $220 \pm 70$ & .02 \\
\hline Atrial fibrillation or flutter & 1143 & $39(3.4)$ & 116 & $0(0)$ & .04 \\
\hline Peripheral arterial disease & 1150 & $35(3.0)$ & 116 & $4(3.4)$ & .8 \\
\hline Hypertension & 1150 & $619(54)$ & 116 & $62(53)$ & .9 \\
\hline \multicolumn{6}{|l|}{ Noncardiac comorbidity } \\
\hline \multicolumn{6}{|l|}{ Diabetes } \\
\hline Pharmacologically treated & 1150 & $58(5.0)$ & 116 & $2(1.7)$ & .11 \\
\hline Insulin treated & 1150 & $23(2.0)$ & 116 & $1(0.87)$ & .4 \\
\hline Non-insulin treated & 1150 & $43(3.7)$ & 116 & $1(0.87)$ & .11 \\
\hline Potassium $\left(\mathrm{mmol} \cdot \mathrm{L}^{-1}\right)$ & 1147 & $4.1 \pm 0.56$ & 116 & $4.1 \pm 0.53$ & .5 \\
\hline Glucose $\left(\mathrm{mg} \cdot \mathrm{dL}^{-1}\right)$ & 1150 & $94 \pm 20$ & 116 & $92 \pm 18$ & .04 \\
\hline Creatinine $\left(\mathrm{mg} \cdot \mathrm{dL}^{-1}\right)$ & 1149 & $1.01 \pm 0.66$ & 116 & $1.01 \pm 0.78$ & .5 \\
\hline Cockcroft-Gault creatinine clearance & 1149 & $95 \pm 30$ & 116 & $97 \pm 25$ & .2 \\
\hline Hematocrit $(\%)$ & 1150 & $40 \pm 5.0$ & 116 & $41 \pm 4.8$ & .2 \\
\hline \multicolumn{6}{|l|}{ Operative details } \\
\hline \multicolumn{6}{|l|}{ Mitral valve surgery } \\
\hline Repair & 1150 & $1041(91)$ & 116 & $112(97)$ & .03 \\
\hline Replacement & 1150 & $109(9.5)$ & 116 & $4(3.4)$ & .03 \\
\hline \multicolumn{6}{|l|}{ Incision/approach } \\
\hline Full sternotomy & 1016 & 279 (27) & 116 & $14(12)$ & .0003 \\
\hline $\begin{array}{l}\text { Minimally invasive (hemisternotomy, } \\
\text { thoracotomy, or robotic) }\end{array}$ & 1016 & 737 (73) & 116 & $102(88)$ & .0003 \\
\hline Robotic & 1150 & 389 (34) & 116 & $45(39)$ & .3 \\
\hline Year of operation & 1150 & & 116 & & $<.0001$ \\
\hline 2010 & & $365(32)$ & & $0(0)$ & \\
\hline 2011 & & $360(31)$ & & $0(0)$ & \\
\hline 2012 & & $299(26)$ & & $16(14)$ & \\
\hline 2013 & & $126(11)$ & & $100(86)$ & \\
\hline
\end{tabular}

$S D$, Standard deviation; NYHA, New York Heart Association; $L V$, left ventricular. *Patients with data available. 
TABLE E3. Factors associated with use of del Nido solution in mitral valve operations

\begin{tabular}{lccc}
\hline \multicolumn{1}{c}{ Factor } & Estimate \pm SE & $\boldsymbol{P}$ value & Reliability $(\%) *$ \\
\hline Greater height (taller) $\dagger$ & $-2.3 \pm 0.92$ & .014 & 55 \\
Lower TR grade & $-0.93 \pm 0.28$ & .0011 & 93 \\
Heart failure & $1.4 \pm 0.24$ & $<.0001$ & 99 \\
Smoking & $-0.97 \pm 0.40$ & .02 & 51 \\
Thinner posterior wall thickness $\ddagger$ & $-2.3 \pm 0.58$ & $<.0001$ & 94 \\
Larger left atrial volume (index) $\ddagger$ & $0.87 \pm 0.29$ & .002 & 90 \\
Approach & & & \\
Less-invasive & $1.5 \pm 0.34$ & $<.0001$ & .003 \\
$\quad$ Robotic & $-1.16 \pm 0.39$ & .009 & 100 \\
\hline Intercept & $-3.8 \pm 1.4$ & - \\
\hline
\end{tabular}

C-statistic $=.80 . S E$, Standard error; $T R$, tricuspid regurgitation. *Percentage of times factor appeared in 500 bootstrap models. $\dagger(180 / \text { height })^{2}$, inverse squared transformation $\ddagger$ Logarithmic transformation.

TABLE E4. Postoperative troponin T levels after aortic valve and mitral valve surgery according to type of cardioplegia

\begin{tabular}{|c|c|c|c|c|}
\hline \multirow[b]{2}{*}{ Parameter } & \multicolumn{2}{|c|}{ Aortic valve surgery } & \multicolumn{2}{|c|}{ Mitral valve surgery } \\
\hline & Estimate \pm SE & $\boldsymbol{P}$ & Estimate \pm SE & $\boldsymbol{P}$ \\
\hline Ischemic time* & $0.39 \pm 0.103$ & .0002 & $0.31 \pm 0.055$ & $<.0001$ \\
\hline Ischemic time (h) in del Nido group (interaction) $\dagger$ & $-0.34 \pm 0.36$ & .3 & $-0.25 \pm 0.21$ & .3 \\
\hline$\underline{\text { de Nido group } \dagger}$ & $0.19 \pm 0.30$ & .5 & $0.22 \pm 0.26$ & .4 \\
\hline Intercept & $-1.8 \pm 0.122$ & $<.0001$ & $-1.3 \pm 0.105$ & $<.0001$ \\
\hline
\end{tabular}

Troponin T modeled on natural logarithmic scale, $\log (\text { troponin T). } S E \text {, Standard error. *(Hours })^{2}$, squared transformation. $\dagger$ Versus Buckberg cardioplegia.

TABLE E5. Postoperative left ventricular ejection fraction after aortic valve and mitral valve surgery according to type of cardioplegia

\begin{tabular}{|c|c|c|c|c|}
\hline \multirow[b]{2}{*}{ Parameter } & \multicolumn{2}{|c|}{ Aortic valve surgery } & \multicolumn{2}{|c|}{ Mitral valve surgery } \\
\hline & Estimate \pm SE & $P$ value & Estimate $\pm \mathrm{SE}$ & $P$ value \\
\hline Preoperative LV ejection fraction in Buckberg group & $0.63 \pm 0.103$ & $<.0001$ & $0.15 \pm 0.108$ & .16 \\
\hline Preoperative LV ejection fraction in del Nido group & $0.78 \pm 0.076$ & $<.0001$ & $0.25 \pm 0.125$ & .05 \\
\hline del Nido group* & $-9.5 \pm 7.54$ & .2 & $-7.9 \pm 10.2$ & .4 \\
\hline Ischemic time (min) & $0.062 \pm 0.047$ & .19 & $0.014 \pm 0.0208$ & .5 \\
\hline Intercept & $17 \pm 7.12$ & .02 & $44 \pm 6.81$ & $<.0001$ \\
\hline
\end{tabular}

